Original Article

\title{
Frequency and Outcomes of Organophosphate Poisoning at Tertiary Care Hospital in Nawabshah
}

\author{
Shahla Imran, Ejaz Ahmed Awan, Muhammad Ismail Salim Memon, Afzal Memon
}

\section{ABSTRACT}

OBJECTIVE: This study aims to determine the frequency of organophosphate poisoning outcomes at tertiary care hospital at Nawabshah.

DESIGN: Descriptive Study.

SETTING: Intensive Care Unit at Peoples University of Medical and Health Sciences for Women, Nawabshah.

MATERIAL AND METHOD: A retrospective study of 387 patients of organophosphate poisoning admitted in Intensive Care Unit at Peoples University of Medical and Health Sciences for Women, Nawabshah, catering all cases from urban and rural areas, during the years January 2013 to December 2015. The Intensive Care Unit is fully equipped with all modern equipment to treat cases of poisoning. The record of the patients were reviewed and the data was entered in proforma for further analysis. The variable considered were gender, age and yearly outcome was presented as frequencies and percentage whereas age was presented as mean \pm SD.

RESULTS: A total of 387 cases organophosphate poisoning were reported in our hospital between 2013 and 2015. The age of study population in our study was $26.14 \pm 10.086$ years with predominance of males $(62.5 \%)$. The highest number of cases $(42.1 \%)$ were reported during 2013 with the least $(23.3 \%)$ in 2014. Moreover, $275(71.1 \%), 105(27.1 \%)$ and $7(1.8 \%)$ cases were cured, expired and referred during the period of three years i.e. 2013 to 2015.

CONCLUSION: Organophosphate poisoning cases were more common among males. Youth is predominant population for organophosphate poisoning which draws immediate attention for public health policy makers, by educating the public through print and electronic media specially television with dramatize shots.

KEYWORDS: organophosphate poisoning, deliberate self-poisoning, homicidal and accidental poisoning.

This article may be cited as: Imran S, Awan EA, Memon MIS, Memon A. Frequency and Outcomes of Organophosphate Poisoning at Tertiary Care Hospital in Nawabshah. J Liaquat Uni Med Health Sci. 2017;16(02):118-20. doi: 10.22442/jlumhs.171620518

\section{INTRODUCTION}

Organophosphate (OP) compounds are used as pesticides, insecticides, herbicides, and chemical battle agents ${ }^{1}$. According to the World Health Organization (WHO), three million people get poisoned with organophosphate compounds with a death rate of 250,000 per annum, particularly in Asian countries ${ }^{1,2}$, specially in Pakistan, India, and Bangladesh, organophosphate compounds (pesticides) are a significant cause of poisoning and contributive to the increasing morality from poisoning-related deaths ${ }^{3}$. Noticeably, organophosphate-related intentional poisoning was reported as $65-79.2 \%$ in developing countries, 40$60 \%$ in African countries, and $10-36.2 \%$ in developed countries ${ }^{4}$. Although mortality in OP poisoning depends on various factors including the time of the treatment, amount of the ingested substance, respiratory support etc, the mortality rate varies be- tween 3 to $25 \%{ }^{1,5}$.

Most cases of acute poisoning are the result of self-poisoning with the intention of suicide ${ }^{3}$. Moreover, suicidal attempt or intention has been reported to be the widespread method of OP poisoning ${ }^{1,6}$. Overall mortality due to self-poisoning in low middle-income countries is $10-20 \%$, which is much higher than the $0.5-1 \%$ of the high-income countries, owing to lack of emergency medical services ${ }^{7}$. However, coincidental exposure is more widespread female housewives and children ${ }^{4}$. Additionally, majority of patients in acute poisoning are young (ageing between 21-30 years) with mean age of 32 in different studies ${ }^{3}$. There are several studies conducted in Karachi, Islamabad, Peshawar and other big cities in Pakistan regarding the cases of OP poisoning but there is scarcity of literature on this topic from small, rural areas of the country particularly from interior sindh covering a major portion of the province ${ }^{3,4,6-8}$. Therefore, this 
study was conducted to determine the frequency of organophosphate poisoning in and its outcomes in a tertiary care hospital in Nawabshah.

\section{MATERIAL AND METHOD}

Following the approval of institutional ethical committee, this descriptive study was conducted. Data from the register of Intensive Care Unit at Peoples University of Medical and Health Sciences for Women, Nawabshah catering all cases from urban and rural areas, during the years January 2013 to December 2015. The Intensive Care Unit is fully equipped with all modern equipment to treat cases of poisoning. The records of the patients were reviewed and the data was entered in proforma for further analysis. The variables conceded were gender, age and outcome was presented as frequencies and percentage whereas age was presented as mean $\pm S D$.

Data entry and analysis was done through Microsoft Excel 2007 and SPSS version 20 respectively. Gender, cases by year and outcome was presented as frequencies and percentages whereas age was presented as mean $\pm S D$. Moreover, frequency tables and cross tabulation was used to present the study findings.

\section{RESULTS}

Out of the total 387 cases of organophosphate poisoning, there was $242(62.5 \%)$ males. The mean age of the patients was 26.14 years in the range of 10 to 65 years [Table I]. There were 163 (42.1\%), 90 (23.3\%) and 134 (34.6\%) cases during 2013, 2014 and 2015 respectively. Moreover, 275 (71.1\%), 105 $(27.1 \%)$ and $7(1.8 \%)$ cases were cured, expired and referred during the period of three years i.e. 2013 to 2015 [Table II].

The highest number of cases reported in 2013 with male predominance (106/163) with the least number of cases during 2014. There was a consistent male predominance seen in the cases reported for organophosphate poisoning during 2013 and 2015 [Table III].

\section{TABLE I: DEMOGRAPHIC INFORMATION OF STUDY POPULATION AND NUMBER OF CASES BY YEAR}

\begin{tabular}{|l|c|c|c|}
\hline \multicolumn{2}{|c|}{ Parameter } & $\begin{array}{c}\text { Frequency } \\
\text { (n=387) }\end{array}$ & Percentage \\
\hline \multirow{2}{*}{ Gender } & Female & 145 & 37.5 \\
& Male & 242 & 62.5 \\
\hline \multirow{3}{*}{ Year } & 2013 & 163 & 42.1 \\
& 2014 & 90 & 23.3 \\
& 2015 & 134 & 34.6 \\
\hline Age (years) & \multicolumn{2}{|l}{ Mean (SD): 26.14 (10.086) } & Range:10-65 \\
\hline
\end{tabular}

TABLE II: CROSS TABULATION OF OUTCOMES OF CASES BY YEAR

\begin{tabular}{|l|c|c|c|c|}
\hline \multicolumn{1}{|c|}{ Year } & Cured & Expired & Referred & Total \\
\hline 2013 & 119 & 42 & 2 & 163 \\
\hline 2014 & 66 & 22 & 2 & 90 \\
\hline 2015 & 90 & 41 & 3 & 134 \\
\hline Total & 275 & 105 & 7 & 387 \\
\hline
\end{tabular}

TABLE III: CROSS TABULATION OF OUTCOMES OF CASES BY GENDER

\begin{tabular}{|l|c|c|c|}
\hline \multicolumn{1}{|c|}{ Year } & Female & Male & Total \\
\hline 2013 & 57 & 106 & 163 \\
\hline 2014 & 32 & 58 & 90 \\
\hline 2015 & 56 & 78 & 134 \\
\hline Total & 145 & 242 & 387 \\
\hline
\end{tabular}

\section{DISCUSSION}

The problem of poisoning is increasing in developing countries including Pakistan. We received 387 cases of organophosphate poisoning between 2013 and 2015 with $27.1 \%$ mortality rate. A study reported mortality rate of $18 \%$ while others reporting it over $20 \%$ receiving 500-1000 patients every year ${ }^{8}$. Although mortality in OP poisoning depends on various factors including the time of the treatment, amount of the ingested substance, respiratory support etc. The mortality rate varies between 3 to $25 \%{ }^{1}$. Organophosphate poisoning is the major cause of mortality and morbidity in the third world countries like Pakistan, accounting for a huge number of admissions in emergency departments and intensive care units ${ }^{8}$. Several studies from Pakistan reported that the Intensive care units should be supported with modern equipments because $40 \%$ cases of OP poising with high mortality rate are because of lack of facilities ${ }^{4,8}$. In a review from Pakistan on 1900 emergency cases, there were $40 \%$ cases of acute poisoning where OP has both the largest number and highest mortality 9,10 . Another study Conducted on the patients admitted at Intensive Care Unit Karachi showed that $7.69 \%$ patients of organophosphate poisoning died due to complications like acute respiratory distress syndrome secondary to aspiration pneumonia ${ }^{10,11}$.

In this study, we had preponderance of males (62.5\%) and the mean age of patients being 26.14 years. These findings were consistent with previous reports with $78 \%, 90.38 \%$ and $77.14 \%$ males, however, other study reported female preponderance $(56.75 \%)^{8,12}$. Likewise, previous studies have reported findings 
similar with predominance of death due to organophosphate poisoning in young population particularly male ${ }^{4,8,13}$.

\section{CONCLUSION}

Although the study address major issue of organophosphate poisoning in a rural setting hospital, there is some limitations of the study to be addressed. Firstly, study was limited to one setting only. Secondly, the data was obtained from medical records. Finally, due to limited data in patient files, many details including the time of ingestion, dose of the poison and similar information was missing.

Organophosphate poisoning cases were more common among males. Youth is predominant population for organophosphate poisoning which draws immediate attention for public health policy makers, by educating the public through print and electronic media specially television with dramatize shots.

\section{REFERENCES}

1. Gündüz $E$, Dursun $R$, Icer $M$, et al. Factors affecting mortality in patients with organophosphate poisoning. J Pak Med Assoc. 2015; 65 (9):967-72.

2. Balali-Mood $M$, Balali-Mood $K$, Moodi $M$, Balali-Mood B. Health aspects of organophosphorous pesticides in Asian countries. Iranin J Public Health. 2012; 41(10): 1-14.

3. Rahim F, Ullah F, Haroon M, Ashfaq M, Afridi AK. Acute poisoning treated in medical intensive care unit. Gomal J Med Sci 2016; 14(3):129-32.

4. Ahmed A, Ali L, Shehbaz L, et al. Prevalence and characteristics of organophosphate poisoning at a tertiary care centre in Karachi, Pakistan. Pak J Surg. 2016; 32(4):269-73.
5. Calvert GM, Plate DK, Das $R$, et al. Acute occupational pesticide related illness in the US, 1998-1999: Surveillance findings from the SENSOR pesticides program. Am $\mathrm{J}$ Ind Med. 2004; 45(1):14-23.

6. Shaikh JM, Siddiqui FG, Soomro AG. Management of acute organophosphorus insecticide poisoning: An experience at a university hospital. J Liaquat Uni Med Health Sci. 2008; 7(2):97-101.

7. Khan NU, Pérez-Núñez $R$, Shamim $N$, et al. Intentional and unintentional poisoning in Pakistan: a pilot study using the Emergency Departments surveillance project. BMC Emerg Med. 2015; 15(Suppl 2):S2.

8. Shaikh MA. Mortality in patients presenting with organophosphorus poisoning at Liaquat University of Medical and Health Sciences. Pak J Med Sci. $2011 ; 27(5): 1022-4$.

9. Jamil $\mathrm{H}$. Acute poisoning: A review of 1900 cases. J Pak Med Assoc. 1990; 40(6):131-3.

10. Mohiuddin H, Siddiqi R, Aijaz P. Pesticide poisoning in Pakistan: the need for public health reforms. Public Health. 2016; 141:185.

11. Hussain AM, Sultan ST. Organophosphorus insecticide poisoning: management in surgical intensive care unit. J Coll Physicians Surg Pak. 2005; 15(2):100-2.

12. Javed A, Waqar F, Ahmed S, Rahman AS, Jamal $Q$, Hussain T. Different Patterns of ECG in Organophosphate Poisoning and Effect on Mortality.Pak Heart J. 2016; 49(3):121-5.

13. Jan A, Khan MJ, Khan MTH, Khan MTM, et al. Poisons Implicated in Homicidal, Suicidal and Accidental Cases in North-West Pakistan. J Ayub Med Coll Abbottabad. 2016; 28(2):308-11.
AUTHOR AFFILIATION:

Dr. Shahla Imran (Corresponding Author)

Assistant Professor

Department of Forensic Medicine \& Toxicology

Bilawal Medical College

Liaquat University of Medical \& Health Sciences

Jamshoro, Sindh-Pakistan.

Email: shahla96@yahoo.com

Dr. Ejaz Ahmed Awan

Assistant Professor

Department of Forensic Medicine \& Toxicology

Peoples University of Medical \&

Health Sciences for Women

Nawabshah (SBA), Sindh-Pakistan.

\section{Dr. Muhammad Ismail Salim Memon}

Assistant Professor

Department of Forensic Medicine \& Toxicology

Khairpur Medical College

Khairpur Mir's, Sindh-Pakistan.

\section{Dr. Afzal Memon}

Professor

Department of Forensic Medicine \& Toxicology

Indus Medical College

Tando Muhammad Khan, Sindh-Pakistan. 